\title{
Effects of density dependence, zooplankton and temperature on blue whiting Micromesistius poutassou growth
}

\author{
Trenkel Verena ${ }^{1, *}$, Lorance Pascal ${ }^{1}$, Fässler S. M. M. ${ }^{2}$, Høines Å. S. ${ }^{3}$
}

${ }^{1}$ Institut Français de Recherche pour l'Exploitation de la Mer (Ifremer); rue de I'Île d'Yeu, BP 21105 44311 Nantes cedex 3 France

${ }^{2}$ Wageningen Institute for Marine Resources and Ecosystem Studies (IMARES); P. O. Box 681970 AB IJmuiden the Netherlands

${ }^{3}$ Institute of Marine Research (IMR); NO-5817 Bergen Norway

* Corresponding author : Verena Trenkel, Tel.: +33 240374000 ;

email address : verena.trenkel@ifremer.fr

\begin{abstract}
:
Blue whiting Micromesistius poutassou mean total length at age in the north-east Atlantic Ocean was found to vary by around $\pm 6 \%$ during the period $2004-2011$ and mean mass at age by $\pm 22 \%$ during the years 1981-2013. Linear modelling provided strong evidence that these phenotypic growth variations can be explained by trophic conditions, mainly negative density dependence and also food availability, and a negative long-term temperature effect on asymptotic siz
\end{abstract}

Keywords : environmental effect, food availability, trophic conditions, von Bertalanffy 


\section{Introduction}

In the north-east Atlantic massive changes in both abundance and distribution of blue whiting Micromesistius poutassou (Risso 1827) have occurred over the last two decades (Trenkel et al., 2014). The recruitment to the blue whiting stock experienced a four-fold increase during the period 1996-2005 (ICES, 2011b). After this period of high recruitment the situation returned to the low levels seen before 1996 and then recovered to above average recruitment from 2011 (ICES, 2013b). While several hypotheses have been put forward to explain these large recruitment changes in terms of processes leading to changes in survival rates from eggs to recruits (Payne et al., 2012), this manuscripts investigates the evidence for concurrent changes in somatic growth, which might or might not be linked to changes in survival.

Phenotypic variability of somatic growth due to trophic conditions has been described for several species, including pelagic species such as herring Clupea harengus L. 1758 (Shin and Rochet, 1998) and capelin Mallotus villosus (Müller 1776) (Obradovich et al., 2014). Trophic conditions can be modified not only by changes in the number of competitors, i.e. density-dependence, but also by changes in prey production, i.e. density-independent factors. With respect to density-dependent processes, the ideal free distribution theory predicts that individuals should spread into less suitable habitats when abundance increases (Fretwell and Lucas, 1969). For $M$. poutassou, spatial spreading has been observed for young-of the-year in the Bay of Biscay (Persohn et al., 2009) and the Barents Sea (Heino et al., 2008). It is not known however, whether these marginal habitats had poorer feeding conditions. For Pacific herring Clupea pallasii Valenciennes 1847, Reum et al. (2013) found that the habitats occupied only by large year classes were indeed less rich in food.

Prey availability for all life stages, but in particular for larvae and juveniles is expected to affect growth and survival as body mass is negatively related to natural morality (Lorenzen, 1996). The diet of larval M. poutassou consists predominately of eggs, nauplii and copepodites of Calanus spp., Pseudocalanus spp., Arcatia spp. and Oithona spp., with little or no phytoplankton (Conway, 1980; Hillgruber and Kloppmann, 1999; Gonzalez-Quiros and Anadon, 2001). Older M. poutassou feed on copepods, euphausiids and amphipods in varying proportions depending on region, depth and fish size (Cabral and Murta, 2002; Langøy et al., 2012). The main feeding grounds of the M. poutassou stock are found in the Norwegian Sea, to which individuals return after spawning along the Irish-Scottish shelf edge in spring [see summary of life history in Trenkel et al. (2014)].

In addition to trophic induced phenotypic growth variations, temperature and oxygen also affect growth (Pörtner and Knust, 2007). For example, Brunel and DickeyCollas (2010) found a negative relationship between mean experienced temperature and asymptotic mass across geographically distributed $C$. harengus stocks and a positive one for the growth rate $k$. Baudron et al. (2014) interpreted multi-decadal variations in asymptotic length estimates by cohort of several species in the North Sea as being caused by the increase in bottom water temperature, but they did not investigate alternative explanations such as food availability or density-dependence. Micromesistius poutassou larval growth rates have been found to vary across the distribution range (Bailey and Heath, 2001; Brophy and King, 2007), concomitant with temperature and salinity gradients (Bailey and Heath, 2001). Such relationships have not been investigated for older M. poutassou.

To shed light on the importance and the factors affecting $M$. poutassou phenotypic growth rate variations the following questions were studied in this paper: i) 
How much phenotypic variability exists in $M$. poutassou growth? ii) Can densitydependence and food availability explain growth variability? iii) Is there evidence for a temperature effect on asymptotic size? To address these questions modified von Bertalanffy growth models were fitted to $M$. poutassou ng length-at-age and mass-atage data.

\section{MaterialS and Methods}

\subsection{Data sources}

Two data sets were available for this study: individual length and age data by sex from the international $M$. poutassou survey for the period 2004-2011 complemented by individuals collected in 2011 just before and during the survey period onboard a commercial fishing vessel and mean mass-at-age in the catch for ages 1 to 10+ years (both sexes combined) calculated by the ICES stock assessment working group for the period 1981-2013 (ICES, 2014b). Both data sets have shortcomings: the first one is short and the second one comes from the catch and sexes are combined.

The international M. poutassou spawning stock survey takes place in March-April every year (ICES, 2011a). Its main objective is to provide a spawning stock biomass estimate for stock assessment. To interpret the collected acoustic-backscatter information, pelagic trawl sampling is carried out opportunistically and from each haul otoliths of 30-100 individuals are randomly collected for age reading. Information on length (lower $\mathrm{mm}$ or $0.5 \mathrm{~cm}$ ), mass $(\mathrm{g})$, sex and maturity stage as well as the geographic position are stored. These biological data were available for the period 2004 to 2011. The majority of individuals in the data were 1 to 6 years old, but individuals up to age 11 occurred. As age reading becomes more unreliable for older individuals, individuals older than 8 years were removed. Combining these data with the data collected onboard the commercial fishing vessel in 2011, a length data set comprising 7983 females and 8090 males collected during the period 2004 to 2011 was obtained [Fig. 1(a)]. To balance the data as much as possible, only year classes 1999 to 2007 were considered and average length per age and year was calculated prior to model fitting. This mean length-at-age data set is considered representative of the size structure of the M. poutassou population.

The second data set representing mass-at-age in the catch was prepared in the following way. First ages 9+ were removed. Next two data sets corresponding to year classes 1980-1911 and 1995-2011 were prepared to match the time series of available environmental variables. Fig. 1(b) shows the longer data set.

For studying feeding conditions a zooplankton biomass index (dry mass in $\mathrm{g} \mathrm{m}^{-2}$ ) derived from net samples from $200 \mathrm{~m}$ to the surface in the main feeding area in the Norwegian Sea in May was available for the period 1995-2013 (ICES, 2014a); see ICES (2013a) for survey and calculation details. Monthly sea surface temperature (SST) data for the period 1980 to 2012 were extracted from the HADISST data set for the main feeding grounds in the Norwegian Sea and around the Faeroe islands (ICES areas Ila and $\mathrm{Vb}$ ). The spatial SST values $\left(1^{\circ} \times 1^{\circ}\right)$ were averaged by year. For each age class and year, the zooplankton index and the mean annual SST values were then averaged over the life time, from the year of birth to the year of capture, as a proxy for the feeding conditions and temperatures experienced.

To study density dependence estimated $M$. poutassou recruit numbers (age 1) for 1981-2012 were taken from the final stock assessment run carried out by ICES 
(2013b). They were estimated as a random walk independent of the spawning stock, i.e. without assuming a stock-recruit relationship.

\subsection{Model}

The generalized von Bertalanffy somatic growth function for body mass (Essington et al. (2001) (see appendix for model for body length) is :

$$
M(a)=M_{\infty}\left[1-e^{-k(1-d)\left(a-a_{0}\right)}\right]^{(1-d)^{-1}}
$$

where $M(a)$ is mass at age $a, M_{\infty}$ asymptotic mass, $k$ growth rate, $a_{0}$ theoretic age at $M(a)=0$ and $d$ describes the allometric scaling of consumption with body size. The asymptotic mass $M_{\infty}$ depends on $k, d$ and the rate of synthesis per unit of physiological surface $H$

$$
M_{\infty}=\left(H k^{-1}\right)^{(1-d)^{-1}}
$$

Shin and Rochet (1998) adapted the von Bertalanffy growth model to incorporate the relationship between trophic conditions and phenotypic plasticity of fish somatic growth. They showed that the amount of food $B(t)$ available for growth in year $t$ will only affect asymptotic size via its impact on $H(t)$

$$
H(t)=e_{\varepsilon} B(t)[N(t)]^{-1}
$$

with $e_{\varepsilon}$ the energy conversion efficiency and $N(t)$ the number of individuals sharing the resource. Two factors in turn affect the amount of food available, overall prey production $P(t)$ and the proportion of it which is consumed, determined by the prey predation rate $p(t)$ and prey mortality $m_{0}$ due to other predators and factors:

$$
B(t)=p(t)\left[p(t)+m_{0}\right]^{-1} P(t)
$$

To account for the diet of $M$. poutassou the available mean life-time prey production $\bar{P}(t)$ from the year of birth in year $t_{\mathrm{c}}\left(t_{\mathrm{c}}=t-a\right)$ up to year $t$ was modelled as a linear function of the mean life-time zooplankton index described above and denoted $\bar{Z}(t, a)$

$$
\bar{P}(t, a)=\delta+\gamma \bar{Z}(t, a)
$$

where $\delta$ encapsulates the enrichment in prey independent of the biotic conditions. The formulation by Shin \& Rochet (1998) was retained for describing the prey predation rate $p(t)$ as being proportional to the number of competitors $N\left(t_{c}\right)$, here the number of recruits of year class $C$

$$
p\left(t_{c}\right)=\alpha N\left(t_{c}\right)
$$

Putting the elements together the modified von Bertalanffy model for growth of age $a$ in year $t$ accounting for trophic conditions is

$$
M(t, a)=\left\{k^{-1}\left[\theta_{1}+\theta_{2} \bar{Z}(t, a)\right]\left[1+\theta_{3} N\left(t_{c}\right)\right]^{-1}\right\}^{(1-d)^{-1}}\left(1-e^{-k(1-d)\left(a-a_{0}\right.}\right)^{(1-d)^{-1}}
$$


where $\theta_{1}=e_{\varepsilon} \alpha \delta\left(m_{0}\right)^{-1}, \theta_{2}=e_{\varepsilon} \alpha \gamma\left(m_{0}\right)^{-1}$ and $\theta_{3}=\alpha\left(m_{0}\right)^{-1}$. Asymptotic mass is then

$$
M_{\infty}(t, a)=\left\{k^{-1}\left[\theta_{1}+\theta_{2} \bar{Z}(t, a)\right]\left[1+\theta_{3} N\left(t_{c}\right)\right]^{-1}\right\}^{(1-d)^{-1}}=\left[H(t, a) k^{-1}\right]^{(1-d)^{-1}}
$$

Equation (7) will be referred to as mass-VBGF and the equivalent in length as length-VBGF (see appendix). The model assumes that asymptotic size (mass or length) is determined by average life-time trophic conditions up to the sampling date. For comparison an additional model with separate $M_{\infty}\left(L_{\infty}\right)$ values by year class, but without any explanatory variables was used. Finally, temperature effects on growth were investigated by using mean life time SST instead of mean life time zooplankton in equation (7) and (8).

The non-linear model [equation (7)] was fitted by least squares (nls function in $\mathrm{R}$ ( $R$ Core Team, 2014)) setting the allometric scaling parameter to $d=0.75$ as recommended by Temming and Herrmann (2009). To test the significance of density dependence (number of recruits), mean life-time zooplankton and mean life-time SST, six models were compared using Akaike's information criterion (AIC): constant $M_{\infty}\left(L_{\infty}\right)$ model $\left(\theta_{2}=0, \theta_{3}=0\right)$, density-dependent $M_{\infty}\left(L_{\infty}\right)$ model $\left(\theta_{2}=0\right)$, two density-independent $M_{\infty}\left(L_{\infty}\right)$ models $\left(\theta_{3}=0\right.$, mean life time zooplankton or SST) and two models with $M_{\infty}\left(L_{\infty}\right)$ varying with recruit abundance and mean life time zooplankton or SST. Goodness-of-fit was assessed by calculating the squared Pearson correlation coefficient between predicted and observed values. Uncertainty intervals for the implicit $M_{\infty}\left(L_{\infty}\right)$ estimates (setting $a=1$ for models with mean life-time SST or zooplankton) based on the best model (smallest AIC) were obtained by drawing 1000 random parameter values from a multivariate normal distribution with the mean parameter estimates and the estimated variance-covariance matrix, inserting these sampled parameter values into equation (8) and taking the $2.5^{\text {th }}$ and 97.5 th percentile values. The $M_{\infty}\left(L_{\infty}\right)$ values by year class were estimated as random effects using the nlme function in $\mathrm{R}$.

As M. poutassou shows sexual dimorphism in growth (Quéro, 1984) [Fig. 1(a)], separate length-VBGFs were fitted for males and females. This could not be done for the mass-VBGF as the data were only available for both sexes combined. Note that the individual mass data from the survey were not useable as body mass varied strongly with maturity stage.

\section{Results}

Micromesistius poutassou mean length-at-age varied by around $\pm 6 \%$ while massat-age varied by around $\pm 22 \%$ across the time series for all ages. Variations in trophic conditions can explain these variations (Table I). Recruit abundance, thus densitydependence, was the single best explanatory variable for all data sets except male lengths for which it was the second best. Mean life-time zooplankton was the second single best variable for female lengths and the shorter mass data set. Mean life-time temperature alone did not explain any variations in growth except for the longer mass data set. This suggests that though the model with recruit abundance and mean lifetime SST had the smallest AIC values for the length data set, the explanatory power of mean life-time SST is spurious in this case. Therefore for the length data set, the selected best model included a density-dependent effect for both males and females with evidence for mean life-time zooplankton being important as well (Table I). This model explained temporal variations in mean length rather well compared to a length- 
VBGF with constant $L_{\infty}$ [Fig. 2(a \& b)]. The estimated value for $\theta_{2}$ (slope of mean lifetime zooplankton) was negative for males and not significantly different from zero for females (Table II). Thus, increased mean life-time zooplankton led to decreased asymptotic length, at least for males.

The model with density-dependence and mean life-time zooplankton was found to also provide the best fit for the shorter mass data set while it was densitydependence and mean life-time temperature for the longer mass data set (Table I). Zooplankton could not be tested for this longer data set however, due to the lack of data. For the longer mass data set the best mass-VBGF model with mean life-time SST and density-dependence explained a large part of the observed variations in mean mass-at-age, including the large drop in the early 2000s and the subsequent increase [Fig. 3(a)]. The estimated value for $\theta_{2}$ (slope of mean life-time SST) was negative, indicating reduced asymptotic body size in warmer waters (Table II).

The squared correlation between model predictions and observed mean mass- or length-at-age was $>0.93$ for all models and data sets, indicating good model fits (Table I). Visual inspection of residuals indicated no violation of model assumption.

To explore how well trophic conditions and density-dependence explained growth variations among year classes, VBGF models with distinct values of $M_{\infty}\left(L_{\infty}\right)$ for each year class were fitted as random effects (Table I). Year class specific $L_{\infty}$ varied between 35.3 and $37.2 \mathrm{~cm}$ (C.V. 2.1\%) for females and between 30.6 and $33.5 \mathrm{~cm}$ (C.V. 3.2\%) for males, with the variations of the two sexes being in phase although they were estimated independently. Year class specific $M_{\infty}$ for both sexes combined varied from 220 to $291 \mathrm{~g}$ (C.V. 8\%) for year classes 1980 to 2011. For all data sets the AIC values of these VBGF random effect models were larger than those of the selected best VBGFs with explanatory variables. However, the time trends and magnitudes of year class specific $M_{\infty}$ or $L_{\infty}$ values agreed generally well with the estimates derived from the selected best length- and mass-VBGF [Fig. 2(c \& d); Fig. 3(b)]. This general agreement is not surprising. For example, the time trends in year class specific $L_{\infty}$ and $M_{\infty}$ estimates (for $a=1$ ) were similar to the mirror image of recruit estimates [Fig. 4; Fig. 5(a)]. Further, cohort specific $L_{\infty}$ and $M_{\infty}$ estimates tended to be higher for year classes which experienced lower zooplankton biomasses and lower for those that experienced higher SST [Fig. 4; Fig. 5(b)] which is in agreement with the negative signs of their slopes $\theta_{2}$.

\section{Discussion}

The results of this study indicated that substantial interannual variability in $M$. poutassou mean size- and mass-at-age occurred and can be explained by densitydependence (recruit abundance), food availability and experienced temperatures. Here only the impact of explanatory variables on asymptotic size was considered, but as the growth coefficient $k(K)$ is negatively related to asymptotic size $M_{\infty}\left(L_{\infty}\right)$ similar results, but with reversed signs would be expected if variations in growth coefficients were modelled.

Finding density-dependence to be the most important factor is not surprising. Persohn (2009) also found a negative year class abundance effect on the size of juvenile (0-group) M. poutassou in the Bay of Biscay, but no such effect in the North Sea or the Gulf of Lions in the Mediterranean Sea. In the oligotrophic Mediterranean, feeding conditions could always be limiting, which would make it harder to detect density-dependence. Alternatively, the timing of the investigations might be important. 
Reum et al. (2013) found that for C. pallasii, density-dependent limitations of growth only emerged late in the growing season of the first year. Micromesistius poutassou were investigated in the Bay of Biscay by Persohn at al. (2009) using data from the end of the growing season in autumn while the data for the Gulf of Lions were collected in June early during the growing season. In this study both data sets reflected the situation in spring after the first growing season and winter which means that densitydependent effects are expected to be detectable if they exist.

A mechanism expected to reinforce the negative density-dependent effect on growth is linked to the ideal free distribution theory under which the suitability of realized habitats decreases as individuals spread out into less suitable habitat when density increases (MacCall, 1990). Spatial occupancy of demersal M. poutassou juveniles in the Bay of Biscay and the Celtic Sea in autumn was found to be positively linked to abundance, while this seemed to be less the case for the more pelagic adults (Persohn et al., 2009). Similarly, M. poutassou were found to spread into the Barents Sea in years of high abundance (Heino et al., 2008). Corroborating an additional habitat related density-dependent effect would require being able to estimate the actual amount of food available to M. poutassou. Unfortunately there is a lack of data to do so.

Mean life-time zooplankton provided an explanation for both length and mass variations in recent decades. It was negatively related to asymptotic size which can be due to more zooplankton leading to faster growth of those year classes, thus larger $\mathrm{K}$ (k) and consequently smaller asymptotic size. Micromesistius poutassou diet information from years of high and low zooplankton biomass would be needed to evaluate this explanation directly and in more detail. The available information shows strong regional patterns in $M$. poutassou diet composition (Langøy et al., 2012; Pinnegar et al., 2014), but a lack of data precludes any time series analyses, in particular of temporal variations in stomach fullness. Further, not only $M$. poutassou but also Norwegian spring spawning $C$. harengus and Atlantic mackerel Scomber scombrus L. 1758 feed on zooplankton in the Norwegian Sea (Langøy et al., 2012). Thus there is potential not only for intraspecific competition, but also interspecific competition between the feeding activity of the three species (Huse et al., 2012).

Temperature had a negative impact on asymptotic mass only for the longer data set. Baudron et al. (2014) also found a negative relationship between increasing temperature in the North Sea and decreasing asymptotic lengths of haddock Melanogrammus aeglefinus (L. 1758), Norway pout Trisopterus esmarkii (Nilsson 1855) and sole Solea solea (L. 1758). Similarly, chub mackerel Scomber japonicus Hottuyn 1782 length at age 0 was negatively related to SST (Watanabe and Yatsu, 2004). Thus these studies support the present findings of a long-term negative relationship between $M$. poutassou growth changes and temperature. Also, although temperature affects growth directly via its effect on anabolism and catabolism, it can also act indirectly via prey availability so that the apparent temperature relationship does not have to be only directly causal.

Several methodological issues might impact somewhat the results of this study. Possibly the most important one could be a country effect in the interpretation of otolith rings for age determination (ICES, 2011b). To minimize the age reader effect only individuals up to age 8 were included in the study. Second, average SST around the Faroe Islands and in the Norwegian Sea was used as an indicator of the experienced temperature. This can be considered indicative only as individuals are commonly found deeper and not all feed in these areas given the large spatial extent of the population. Third, the available zooplankton biomass index represents the average zooplankton biomass in the epi-pelagic zone (first 200 m) in May in the Norwegian Sea. Again this is 
only a rough proxy for the available zooplankton prey biomass and does not account for specific prey preferences. Fourth, the stock assessment estimate for age 1 (1 January the year following birth) was used as a proxy for year class strength which assumes that the stock assessment estimates were at least correct in relative terms. Finally, though SST, zooplankton biomass and recruit abundance are linked to some degree, using mean life-time SST and mean life-time zooplankton assured some independence between these variables, but possibly not enough, as indicated by mean life-time SST becoming significant when recruit abundance was included in the length models.

In conclusion, this study provides strong evidence for phenotypic growth variations in $M$. poutassou due to trophic conditions, mainly negative densitydependence and a negative zooplankton effect, and a longer term negative temperature effect.

We would like to thank Imares (the Netherlands), IMR (Norway), the Faroes Island Marine Institute, and the Irish Marine Institute for making the survey data available. We are grateful to the crew of the pelagic trawler Joseph Roty 2 for collecting samples. We are grateful to $\mathrm{G}$. Huse for providing the zooplankton index. This study received funding from the European Union Seventh Framework Programme project EURO-BASIN (ENV.2010.2.2.1-1) under grant agreement $n^{\circ} 264933$ and a contract from FROM NORD to Ifremer.

\section{References}

Bailey, M. C. \& Heath, M. R. (2001). Spatial variability in the growth rate of blue whiting (Micromesistius poutassou) larvae at the shelf edge west of the UK. Fisheries Research 50, 73-87.

Baudron, A. R., Needle, C. L., Rijnsdorp, A. D. \& Marshall, C. T. (2014). Warming temperatures and smaller body sizes: synchronous changes in growth of North Sea fishes. Global Change Biology 20, 1023-1031.

Brophy, D. \& King, P. A. (2007). Larval otolith growth histories show evidence of stock structure in Northeast Atlantic blue whiting (Micromesistius poutassou). ICES Journal of Marine Science 64, 1136-1144.

Brunel, T. \& Dickey-Collas, M. (2010). Effects of temperature and population density on von Bertalanffy growth parameters in Atlantic herring: a macro-ecological analysis. Marine Ecology Progress Series 405, 15-28.

Cabral, H. N. \& Murta, A. G. (2002). The diet of blue whiting, hake, horse mackerel and mackerel off Portugal. Journal of Applied Ichthyology 18, 14-23.

Conway, D. V. P. (1980). The food of larval blue whiting, Micromesistius poutassou (Risso), in the Rockall area. Journal of Fish Biology 16, 709-723.

Essington, T. E., Kitchell, J. F. \& Walters, C. J. (2001). The von Bertalanffy growth function, bioenergetics, and the consumption rates of fish. Canadian Journal of Fisheries and Aquatic Sciences 58, 2129-2138.

Fretwell, S. D. \& Lucas, H. L. (1969). On territorial behaviour and other factors influencing habitat distribution in birds. Acta Biotheoretica 19, 16-37.

Gonzalez-Quiros, R. \& Anadon, R. (2001). Diet breadth variability in larval blue whiting as a response to plankton size structure. Journal of Fish Biology 59, 1111-1125.

Heino, M., Engelhard, G. H. \& Godø, O. R. (2008). Migrations and hygrography determine the abundance fluctuations of blue whiting (Micromesistius poutassou) in the Barents Sea. Fisheries Oceanography 17, 153-163.

Hillgruber, N. \& Kloppmann, M. (1999). Distribution and feeding of blue whiting Micromesistius poutassou larvae in relation to different water masses in the 
Porcupine Bank area, west of Ireland. Marine Ecology Progress Series 187, 213-225.

Huse, G., Holst, J. C., Utne, K., Nottestad, L., Melle, W., Slotte, A., Ottersen, G., Fenchel, T. \& Uiblein, F. (2012). Effects of interactions between fish populations on ecosystem dynamics in the Norwegian Sea - results of the INFERNO project Preface. Marine Biology Research 8, 415-419.

(last accessed 8 April 2015).

Langøy, H., Nøttestad, L., Skaret, G., Broms, C. \& Fernö, A. (2012). Overlap in distribution and diets of Atlantic mackerel (Scomber scombrus), Norwegian spring-spawning herring (Clupea harengus) and blue whiting (Micromesistius poutassou) in the Norwegian Sea during late summer. Marine Biology Research 8, 442-460.

Lorenzen, K. (1996). The relationship between body weight and natural mortality in juvenile and adult fish: A comparison of natural ecosystems and aquaculture. Journal of Fish Biology 49, 627-647.

MacCall, A. D. (1990). Dynamic geography of marine fish populations. Seattle, W.A.: University of Washington Press.

Obradovich, S. G., Carruthers, E. H. \& Rose, G. A. (2014). Bottom-up limits to Newfoundland capelin (Mallotus villosus) rebuilding: the euphausiid hypothesis. ICES Journal of Marine Science 71, 775-783.

Payne, M. R., Egan, A., Fässler, S. M. M., Hátún, H., Holst, J. C., Jacobsen, J. A., Slotte, A. \& Loeng, H. (2012). The rise and fall of the NE Atlantic blue whiting. Marine Biology Research 8, 475-487.

Persohn, C. (2009). Sensibilité des populations de poissons aux changements globaux en fonction de leurs traits d'histoire de vie étudiée par une approche empirique. p. 200: University of Brest.

Persohn, C., Lorance, P. \& Trenkel, V. M. (2009). Habitat preferences of selected demersal fish species in the Bay of Biscay and Celtic Sea, North-East Atlantic. Fisheries Oceanography 18, 268-285.

Pinnegar, J. K., Goñi, N., Trenkel, V. M., Arrizabalaga, H., Melle, W., Keating, J. \& Óskarsson, G. (2014). A new compilation of stomach content data for commercially-important pelagic fish species in the Northeast Atlantic. Earth Syst. Sci. Data Discuss. 7 197-223.

Pörtner, H. O. \& Knust, R. (2007). Climate change affects marine fishes through the oxygen limitation of thermal tolerance. Science 315, 95-97.

Quéro, J. C. (1984). Les poissons de mer des pêches françaises. Paris: Grancher.

$\mathrm{R}$ Core Team (2014). R: A language and environment for statistical computing. $R$ Foundation for Statistical Computing, Vienna, Austria. URL http://www.Rproject.org/.

Reum, J. C. P., Essington, T. E., Greene, C. M., Rice, C. A., Polte, P. \& Fresh, K. L. (2013). Biotic and abiotic controls on body size during critical life history stages of a pelagic fish, Pacific herring (Clupea pallasii). Fisheries Oceanography 22, 324-336.

Shin, Y.-J. \& Rochet, M.-J. (1998). A model for the phenotypic plasticity of North sea herring growth in relation to trophic conditions. Aquatic Living Resources 11, 315-324.

Temming, A. \& Herrmann, J. P. (2009). A generic model to estimate food consumption: linking von Bertalanffy's growth model with Beverton and Holt's and Ivlev's concepts of net conversion efficiency. Canadian Journal of Fisheries and Aquatic Sciences 66, 683-700.

Trenkel, V. M., Huse, G., MacKenzie, B., Alvarez, P., Arrizabalaga, H., Castonguay, M., Goñi, N., Grégoire, F., Hátún, H., Jansen, T., Jacobsen, J. A., Lehodey, P., Lutcavage, M., Mariani, P., Melvin, G., Neilson, J. D., Nøttestad, L., Óskarsson, G. J., Payne, M., Richardson, D., Senina, I. \& Speirs, D. C. (2014). Comparative ecology of widely-distributed pelagic fish species in the North Atlantic: 
implications for modelling climate and fisheries impacts. Progress in Oceanography 129, 219-243.

Watanabe, C. \& Yatsu, A. (2004). Effects of density-dependence and sea surface temperature on interannual variation in length-at-age of chub mackerel (Scomber japonicus) in the Kuroshio-Oyashio area during 1970-1997. Fishery Bulletin 102, 196-206.

\section{Electronic References}

ICES (2011a). Report of the Working Group on Northeast Atlantic Pelagic Ecosystems Surveys (WGNAPES). ICES CM 2011/SSGESST:16. Available at: http://www.ices.dk/sites/pub/Publication\%20Reports/Expert\%20Group\%0Report/ SSGESST/2011/WGNAPES11.pdf (last accessed 8 April 2015).

ICES (2011b). Report of the working group on Widely Distributed Stocks (WGWIDE). ICES CM 2011/ACOM:15. Available at: http://www.ices.dk/sites/pub/Publication\%20Reports/Expert\%20Group\%20Repo rt/acom/2011/WGWIDE/WGWIDE\%20Report\%202011.pdf (last accessed 8 April 2015).

ICES (2013a). Interim Report of the Working Group on Integrated Ecosystem Assessments for the Norwegian Sea (WGINOR). ICES CM 2013/SSGRSP:07. Available http://www.ices.dk/sites/pub/Publication\%20Reports/Expert\%20Group\%20Repo rt/SSGRSP/2013/WGINOR13.pdf (last accessed 8 April 2015).

ICES (2013b). Report of the Working Group on Widely Distributed Stocks (WGWIDE). ICES CM 2013/ACOM:15. Available at: http://www.ices.dk/sites/pub/Publication\%20Reports/Expert\%20Group\%20Repo rt/acom/2013/WGWIDE/01\%20WGWIDE\%20-

\%20Report\%20of\%20Working\%20Group\%20on\%20Widely\%20Distributed $\% 20$ Stocks.pdf (last accessed 8 April 2015).

ICES (2014a). Report of the Working Group on Celtic Seas Ecoregion (WGCSE). ICES CM 2014/ACOM:12. Available at: http://www.ices.dk/sites/pub/Publication\%20Reports/Expert\%20Group\%20Repo rt/acom/2014NGCSE/WGCSE 2014.pdf (last accessed 8 April 2015).

ICES (2014b). Report of the Working Group on Widely Distributed Stocks (WGWIDE). ICES CM 2014/ACOM:15. Available at: http://www.ices.dk/sites/pub/Publication\%20Reports/Expert\%20Group\%20Repo rt/acom/2014/WGWIDE/01\%20WGWIDE\%20report\%202014.pdf (last accessed 8 April 2015).

R Core Team (2014). R: A language and environment for statistical computing. $R$ Foundation for Statistical Computing, Vienna, Austria. URL http://www.Rproject.org/. 
Table I. Summary of model performance for Micromesistius poutassou growth models: $\triangle \mathrm{AIC}$ (Akaike's information criteria) and squared correlation between fitted and observed values (in brackets). The models with the smallest AIC have value 0 .

\begin{tabular}{|l|l|l|l|l|}
\hline Model & \multicolumn{2}{|l|}{ Length-VBGF } & \multicolumn{2}{l|}{ Mass-VBGF } \\
\hline & Females & Males & Year classes & Year classes \\
& $\mathrm{n}=52$ & $\mathrm{n}=52$ & $1995-2011$ & $1980-2011$ \\
$\mathrm{n}=115$ & $\mathrm{n}=235$ \\
\hline $\begin{array}{l}\text { Constant } \mathrm{M}_{\infty} / \mathrm{L}_{\infty} \\
\text { Density-dependence }\left(\theta_{2}\right.\end{array}$ & $0(0.98)$ & $13(0.98)$ & $3(0.96)$ & $167(0.91)$ \\
\hline $\begin{array}{l}\text { Zooplankton } \\
\left(\theta_{3}=0\right)\end{array}$ & $6(0.97)$ & $12(0.94)$ & $39(0.95)$ & $10(0.95)$ \\
\hline $\begin{array}{l}\text { SST }\left(\theta_{3}=0\right) \\
\text { Density-dependence \& } \\
\text { zooplankton }\end{array}$ & $2(0.98)$ & $9(0.98)$ & $0(0.97)$ & no data \\
\hline $\begin{array}{l}\text { Density-dependence \& } \\
\text { SST }\end{array}$ & $0(0.98)$ & $0(0.98)$ & $5(0.96)$ & $0.93)$ \\
\hline $\begin{array}{l}\text { Cohort specific } \mathrm{L}_{\infty} / \mathrm{M}_{\infty} \\
\text { (random effect) }\end{array}$ & $18(0.98)$ & $31(0.97)$ & $31(0.97)$ & $40(0.94)$ \\
\hline
\end{tabular}


Table II. Micromesistius poutassou growth model parameter estimates for VBGF models with mean life-time temperature and recruit abundance as explanatory variables. $P$ values are for $t$ tests

\begin{tabular}{|c|c|c|c|}
\hline Parameter & Estimate & S.E. & $P$ \\
\hline \multicolumn{4}{|c|}{ Females (length-VBGF) } \\
\hline$K$ & 0.357 & 0.032 & 0 \\
\hline$a_{0}$ & -2.308 & 0.254 & 0 \\
\hline$\theta_{1}$ & 6.322 & 0.664 & 0 \\
\hline$\theta_{2}$ (zoopl.) & -0.011 & 0.02 & $>0.05$ \\
\hline$\theta_{3}$ (recruit.) & 0.001 & 0.0003 & $<0.05$ \\
\hline \multicolumn{4}{|c|}{ Males (length-VBGF) } \\
\hline$K$ & 0.465 & 0.034 & $<0.001$ \\
\hline$a_{0}$ & -1.956 & 0.2 & $<0.001$ \\
\hline$\theta_{1}$ & 4.536 & 0.369 & $<0.001$ \\
\hline$\theta_{2}$ (zoopl.) & -0.028 & 0.012 & $<0.05$ \\
\hline$\theta_{3}$ (recruit.) & 0.001 & 0.0003 & $<0.05$ \\
\hline \multicolumn{4}{|c|}{ Combined sex (mass-VBGF) Year classes 1995-2011 } \\
\hline$k$ & 0.803 & 0.078 & 0 \\
\hline$a_{0}$ & -4.477 & 0.441 & $<0.001$ \\
\hline$\theta_{1}$ & 0.596 & 0.049 & $<0.001$ \\
\hline$\theta_{2}$ (zoopl.) & -0.0012 & 0.0006 & $<0.05$ \\
\hline$\theta_{3}$ (recruit.) & $9 e-07$ & $1 \mathrm{e}-07$ & $<0.001$ \\
\hline \multicolumn{4}{|c|}{ Combined sex (mass-VBGF) Year classes 1980-2011 } \\
\hline$k$ & 0.843 & 0.063 & $<0.001$ \\
\hline$a_{0}$ & -4.110 & 0.329 & $<0.001$ \\
\hline$\theta_{1}$ & 0.734 & 0.057 & $<0.001$ \\
\hline$\theta_{2}(\mathrm{SST})$ & -0.012 & 0.004 & 0.0009806 \\
\hline$\theta_{3}$ (recruit.) & $1.1 \mathrm{e}-06$ & $1 \mathrm{e}-07$ & $<0.001$ \\
\hline
\end{tabular}




\section{Figures}

Figure 1. (a) Micromesistius poutassou length-at-age data with symbol radius proportional to the number of observations and the ages shifted to show males (squares) and females (circles) separately. (b) Micromesistius poutassou mass-at-age data, lines link data for same year class.
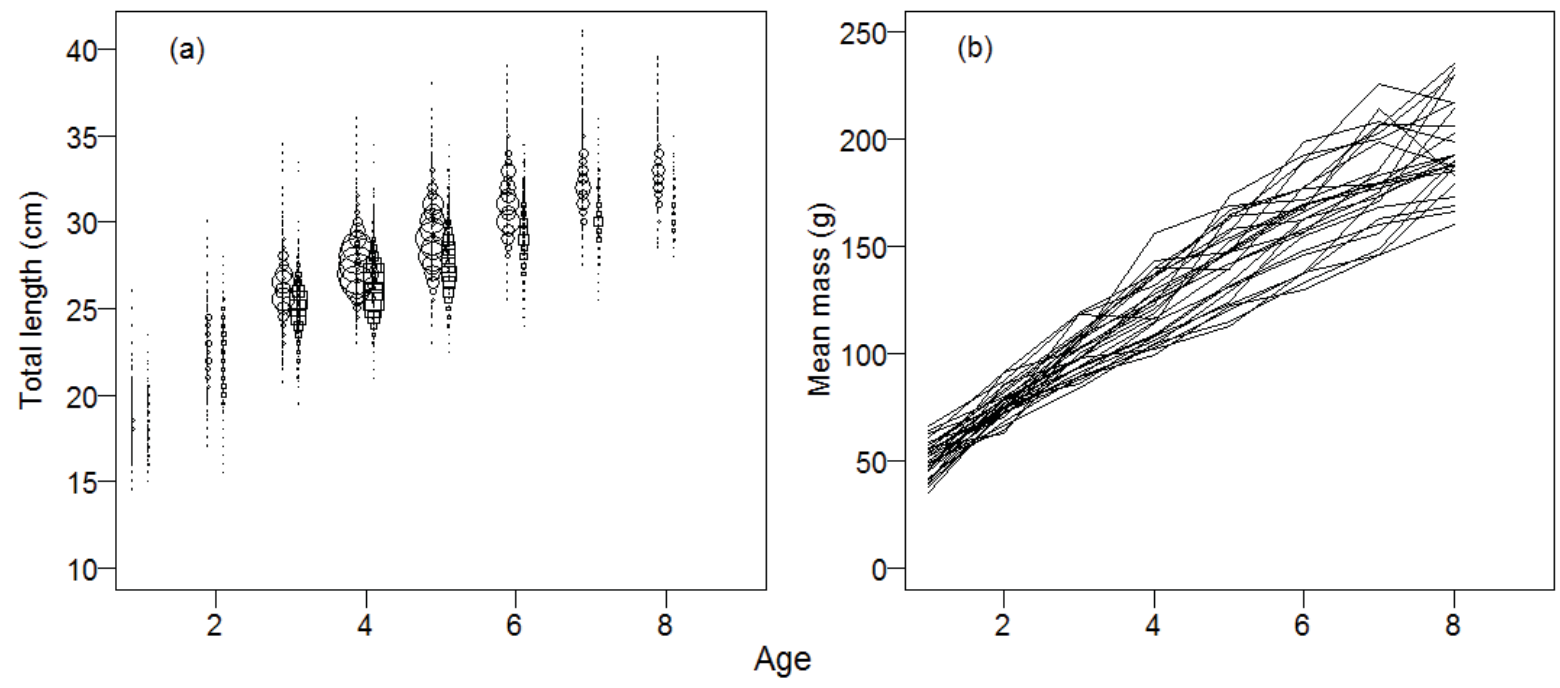
Figure 2. (a) \& (b) Micromesistius poutassou mean length-at-age (symbols) and fitted lengthVBGFs. Fitted length-VBGFs with $L_{\infty}$ varying as a function of recruit abundance and mean life time zooplankton (continuous line) and with constant $L_{\infty}$ (dashed line). (c) \& (d) Estimated $L_{\infty}$ values by year class for length-VBGF with $L_{\infty}$ varying as a function of recruit abundance and mean life time zooplankton for $a=1$ (continuous line, 95\% uncertainty interval in grey) and for length-VBGF with year class specific $L_{\infty}$ estimates (filled circles).
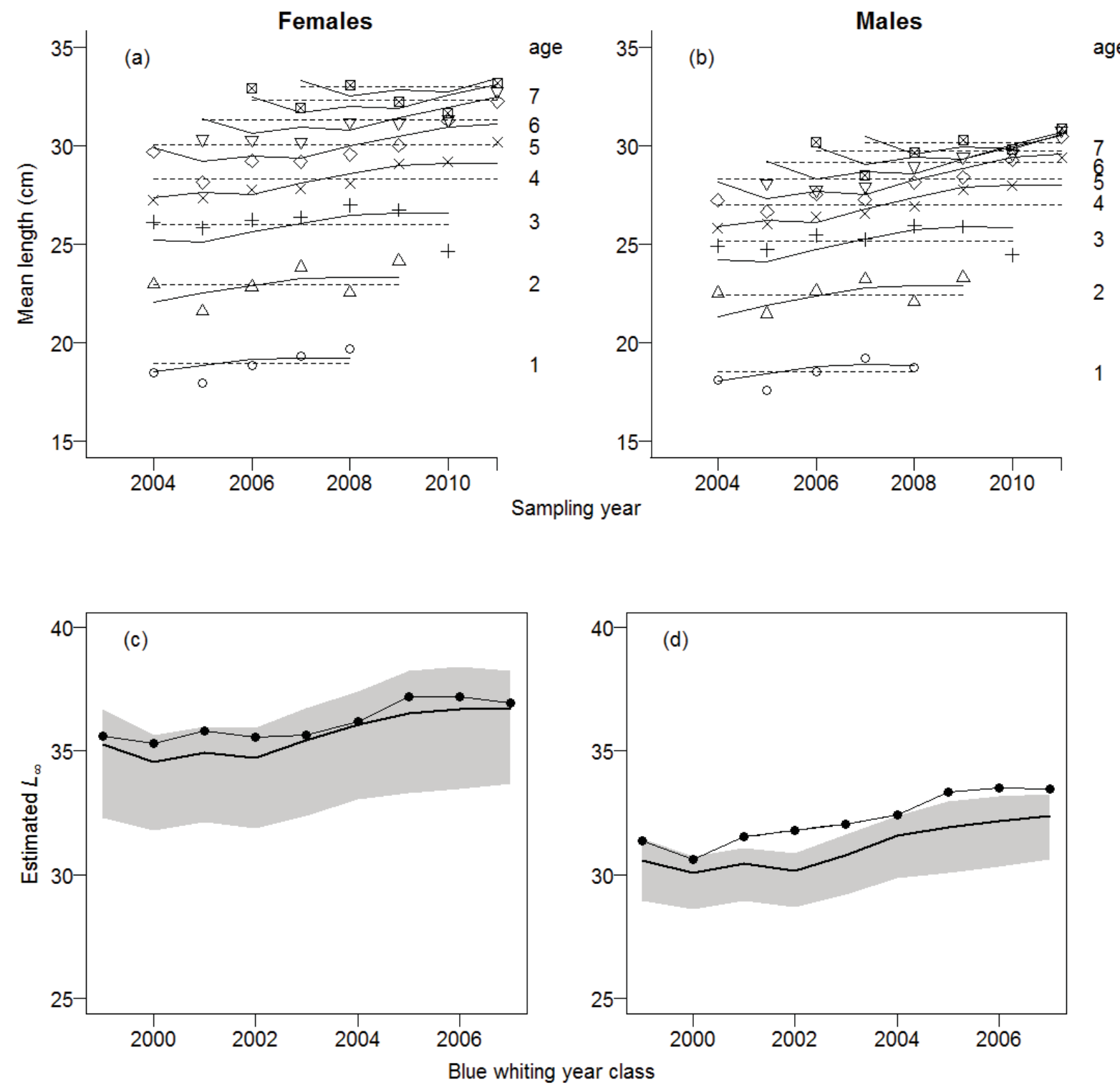
Figure 3. (a) Micromesistius poutassou mean mass-at-age data (symbols) and fitted massVBGFs with $M_{\infty}$ varying as a function of recruit abundance and mean life time SST (continuous line) and with constant $M_{\infty}$ (dashed line). (b) Estimated $M_{\infty}$ values by year class for mass-VBGF with $M_{\infty}$ varying as a function of recruit abundance and mean life-time SST for $a=1$ (continuous line, $95 \%$ uncertainty interval in grey) and for mass-VBGF with year class specific $M_{\infty}$ estimates (filled circles).
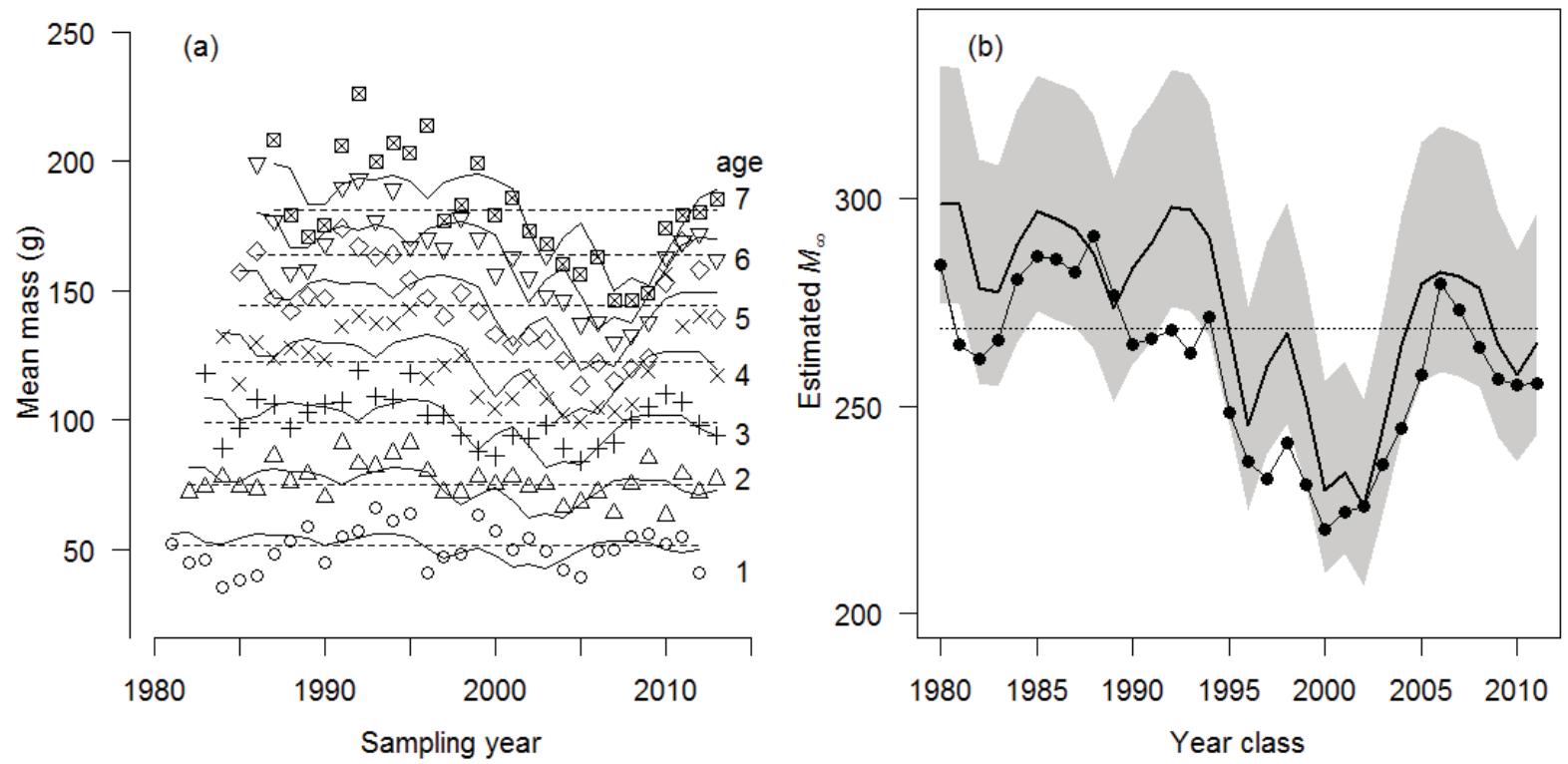

Figure 4. Normalized estimated year class specific $L_{\infty}$ estimates (filled circles) with normalized recruit abundance (cross), mean life-time SST (diamond) and mean life-time zooplankton index (plus) for Micromesistius poutassou averaged by year class. Note that the $\mathrm{y}$-axis has been reversed for recruits to account for the expected inverse effect.

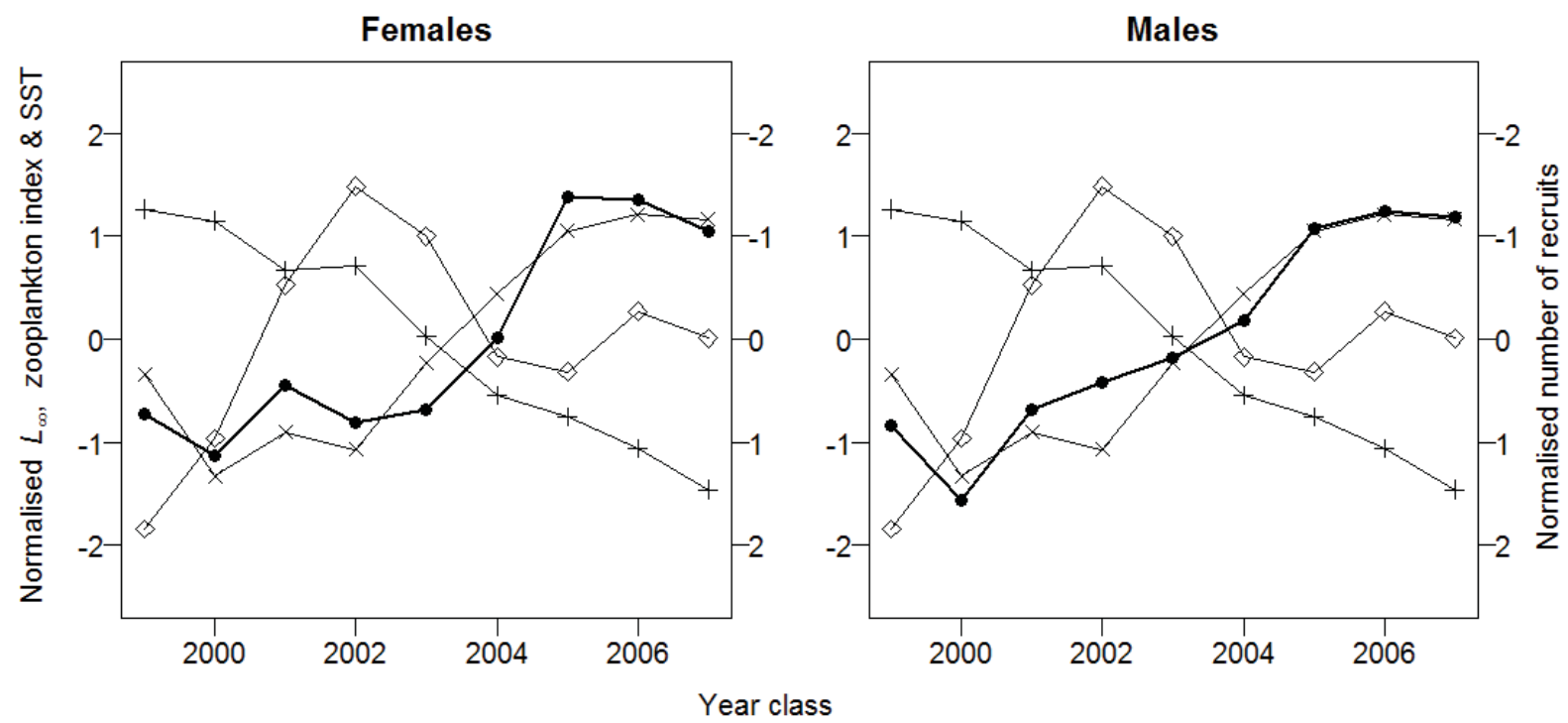


Figure 5. Normalized year class specific $M_{\infty}$ estimates (filled circles) with (a) normalized recruit abundance (cross) and (b) mean life-time SST (diamond) and mean life-time zooplankton index (plus) for Micromesistius poutassou averaged by year class. Note that the $\mathrm{y}$-axis has been reversed for recruits to account for the expected inverse effect.

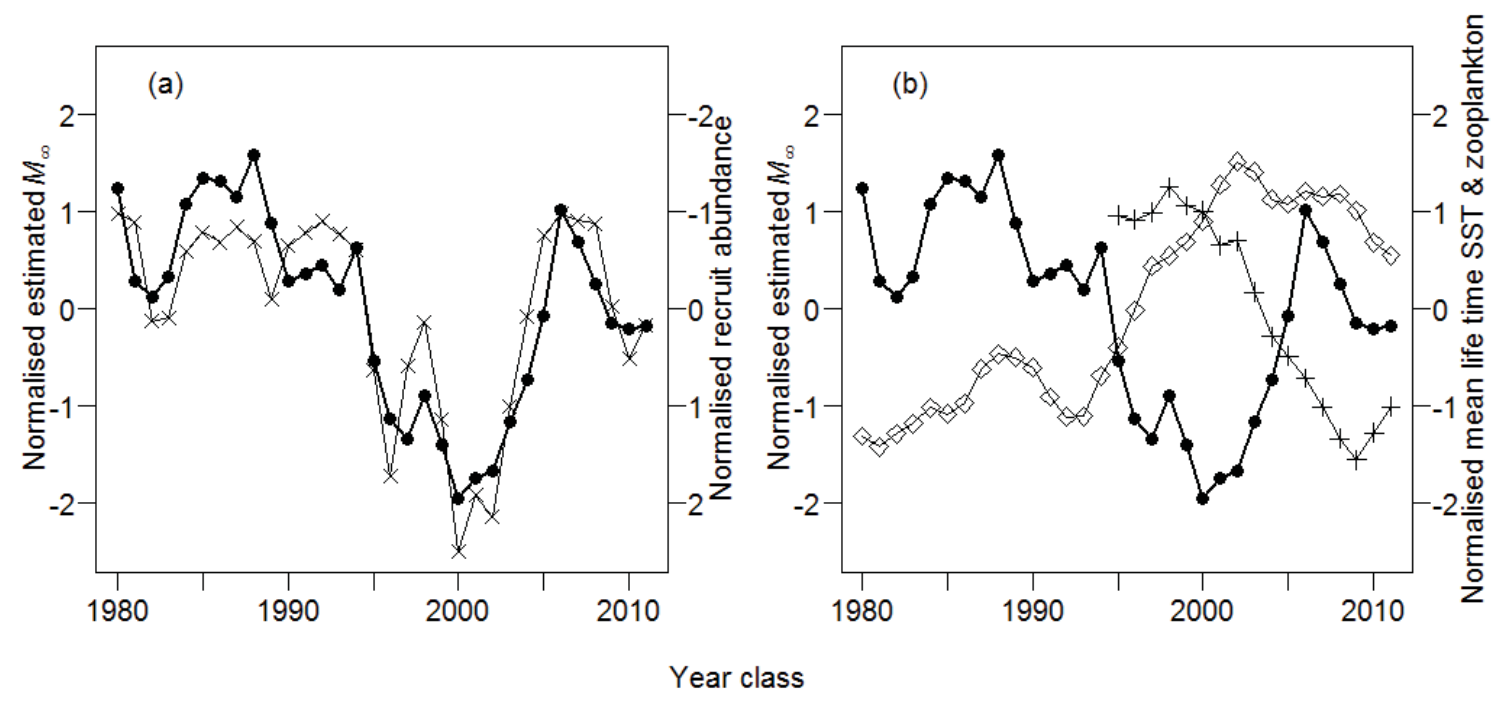




\section{Appendix}

\section{Growth function in length}

The modified length-VBGF for length $L$ at age $a$ in year $t$ accounting for trophic conditions is

$$
L(t, a)=\left\{c^{d-1}(b K)^{-1}\left[\theta_{1}+\theta_{2} \bar{Z}(t, a)\right]\left[1+\theta_{3} N\left(t_{c}\right)\right]^{-1}\right\}^{(1-m)^{-1}}\left[1-e^{-K(1-m)\left(a-a_{0}\right.}\right]^{(1-m)^{-1}}
$$

where $m=b(d-1)+1$ and $c$ and $b$ are parameters of the length-mass relationship $M=c L^{b}$. All other parameters are the same as for the massVBGF [equation (7)]. The growth rate $K$ in length is related to $k$ in mass in equation (1) as $K=k / b$.

Asymptotic length by year class and age is then

$$
L_{\infty}(t, a)=\left\{a^{d-1}(b K)^{-1}\left[\theta_{1}+\theta_{2} \bar{Z}(t, a)\right]\left[1+\theta_{3} N\left(t_{c}\right)\right]^{-1}\right\}^{(1-m)^{-1}}=\left\{\left[a^{d-1} H(t, a)[b K]^{-1}\right\}^{(1-m)^{-1}}\right.
$$

The parameters of the length-mass relationship were obtained by fitting the relationship to the survey data for immature, resting or spent individuals of both sexes only to avoid that variable gonad mass during spawning influenced the parameter values. The results were $c=3.544 \mathrm{H}^{1-6}\left(\mathrm{~S}\right.$.E. $1.417 \mathrm{H}^{-7} 0^{-7}$ ) and $b=3.097$ (S.E. 0.012). 
